\title{
Экспериментальные исследования процесса экструдирования биополимеров и идентификация моделей его отдельных компонентов
}

\author{
Хобин В.А., Егоров В.Б. \\ Одесская национальная академия пищевых технологий
}

\begin{abstract}
Аннотация: Технология экспериментально-эвристического подхода, принятая для разработки математической модели процесса экструдирования биополимеров как объекта управления, показала свою эффективность. На основе ограниченного количества экспериментов была получена физически обоснованная и адекватная модель. Эта эффективность обусловлена тем, что при экспериментально-эвристическом подходе объединяются знания объективные, суть которых - характеристики процесса, получаемые в ходе натурных экспериментов, и знания субъективные, суть которых - понимание разработчиком модели физической сущности протекающих процессов.
\end{abstract}

Ключевые слова: идентификация, математические модели, система автоматического управления, экструдирование, биополимеры.

Предисловие. Проблемы идентификации $[1,2]$ математических модели (ММ) процесса экструдирования биополимеров (ЭБП), т.е. получение математического описания процессов по результатам его целенаправленных экспериментальных исследований, обусловлены его сложностью как объекта управления (ОУ). Причины сложностей подробно рассмотрены в [3]. Они, как уже отмечалось ранее, делают малоконструктивным и аналитический подход к получению моделей.

Экспериментальный подход, в данном случае, хотя и дает гораздо более достоверные результаты о свойствах процесса, но эти результаты отражают лишь частные случаи из общих свойств, которыми обладает процесс ЭБП как ОУ. Попытка получения таких общих свойств на основе экспериментальных данных неизбежно привела бы к необходимости проведения весьма сложных и длительных многофакторных экспериментов, нетривиальных процедур их обработки $[4,5]$. Но и это, к сожалению, оставит открытым вопрос об адекватности модели для технических условий ведения процесса и видов сырья, которые не были охвачены экспериментами.

Принципиально важен тот факт, что ММ процесса ЭБП разрабатывается как модель ОУ. Такая модель, в общем случае, может использоваться двояко: Во-первых, для разработки системы автоматического управления (САУ), например, с использованием процедур имитационного моделирования, где на первое место выходит решение задач устойчивости и динамической точности замкнутых контуров управления. Во-вторых, для использования непосредственно в процессе управления, т.е. для расчета тех или иных управляющих воздействий по модели в разомкнутых цепях САУ. Очевидно, что второе направление применения требует достаточно точных моделей. Но уже на этапе разработки концепции управления процессами ЭБП и вариантов структурных схем САУ от такого применения моделей пришлось отказаться.

Все экспериментальные исследования процессов ЭБП проводились на экструдере Е-150 [6, 7] в рамках разработанного автоматизированного рабочего места (АРМ) исследователя. Графики изменений во времени тех переменных, которые подлежали исследованию и, которые приведены ниже в качестве иллюстраций, построены в редакторе Excel. При этом электронные таблицы с данными сформировались с помощью специально разработанной программы.

Суть исследований: Первоначально, как автономное устройство экструдера, был исследован его вибропитатель по каналу « $\mathrm{u}_{\text {п }}-\mathrm{Q}_{\mathrm{o}}$ д для двух видов продуктов - пшеницы и сои. По результатам исследования были сделаны следующие выводы: а) вибропитатель, как динамическое звено общей системы можно считать безынерционным; б) вибропитатель имеет существенную зону нечувствительности, $u_{n}^{3 н} \approx 10 \%$ у.в., которую можно принять одинаковой для различных видов продукта; в) рабочий диапазон управляющих воздействий вибропитателя не превышает $15 \ldots 20 \% \mathrm{u}_{\text {п }}$, в абсолютных единицах он составляет $10 \ldots(25 \ldots 30) \% \mathrm{u}_{п} ;$ г) изменение объемной производительности в функции $\mathrm{u}_{\text {п }}$ имеет квадратичный характер. Результаты исследований питателя и идентификации моделей его статических характеристик приведены на рис. 1. Предварительные исследования динамики изменения регулируемых переменных, см. рис. 2, подтвердили 

ТЕХНОЛОГІЧНИМИ ПРОЦЕСАМИ

\begin{tabular}{|c|c|c|}
\hline \multirow{2}{*}{$\begin{array}{c}\text { Управляющее } \\
\text { воздействие } \mathrm{u}_{\Pi}, \% \\
\text { мощности, } \\
\text { подводимой к } \\
\text { вибропитателю }\end{array}$} & \multicolumn{2}{|c|}{ Продукт: пшеница } \\
\cline { 2 - 3 } & \multicolumn{2}{|c|}{$\mathrm{Q}_{\mathrm{o}}$} \\
\hline 0 & 0,00 & 0,00 \\
\hline 10 & 11,08 & 17,35 \\
\hline 15 & 41,28 & 65,72 \\
\hline 20 & 124,05 & 177,87 \\
\hline 25 & 190,78 & 233,77 \\
\hline 30 & 283,02 & 350,19 \\
\hline 35 & 328,17 & 462,13 \\
\hline 40 & 534,12 & 534,12 \\
\hline 45 & 614,33 & 687,02 \\
\hline 50 & 782,61 & 759,49 \\
\hline 65 & 1224,49 & 1224,49 \\
\hline 100 & 1628,96 & 1628,96 \\
\hline & &
\end{tabular}

\begin{tabular}{|c|c|c|}
\hline \multirow{2}{*}{$\begin{array}{c}\text { Управляющее } \\
\text { воздействие } \mathrm{u}_{\Pi}, \% \\
\text { мощности, } \\
\text { подводимой к } \\
\text { вибропитателю }\end{array}$} & \multicolumn{2}{|c|}{$\begin{array}{c}\text { Продукт: соя } \\
\text { Производительность питателя } \\
\mathrm{Q}_{\mathrm{o}}, \\
\end{array}$} \\
\hline & Прямой ход & Обратный ход \\
\hline 0 & 0,00 & 0,00 \\
\hline 10 & 6,75 & 13,40 \\
\hline 15 & 40,78 & 61,26 \\
\hline 20 & 124,87 & 137,98 \\
\hline 25 & 212,77 & 254,60 \\
\hline 30 & 292,68 & 299,25 \\
\hline 35 & 324,62 & 392,33 \\
\hline 40 & 520,98 & 497,24 \\
\hline 45 & 560,75 & 656,93 \\
\hline 50 & 849,06 & 849,06 \\
\hline 70 & 1309,09 & 1309,09 \\
\hline 100 & 1463,41 & 1463,41 \\
\hline
\end{tabular}
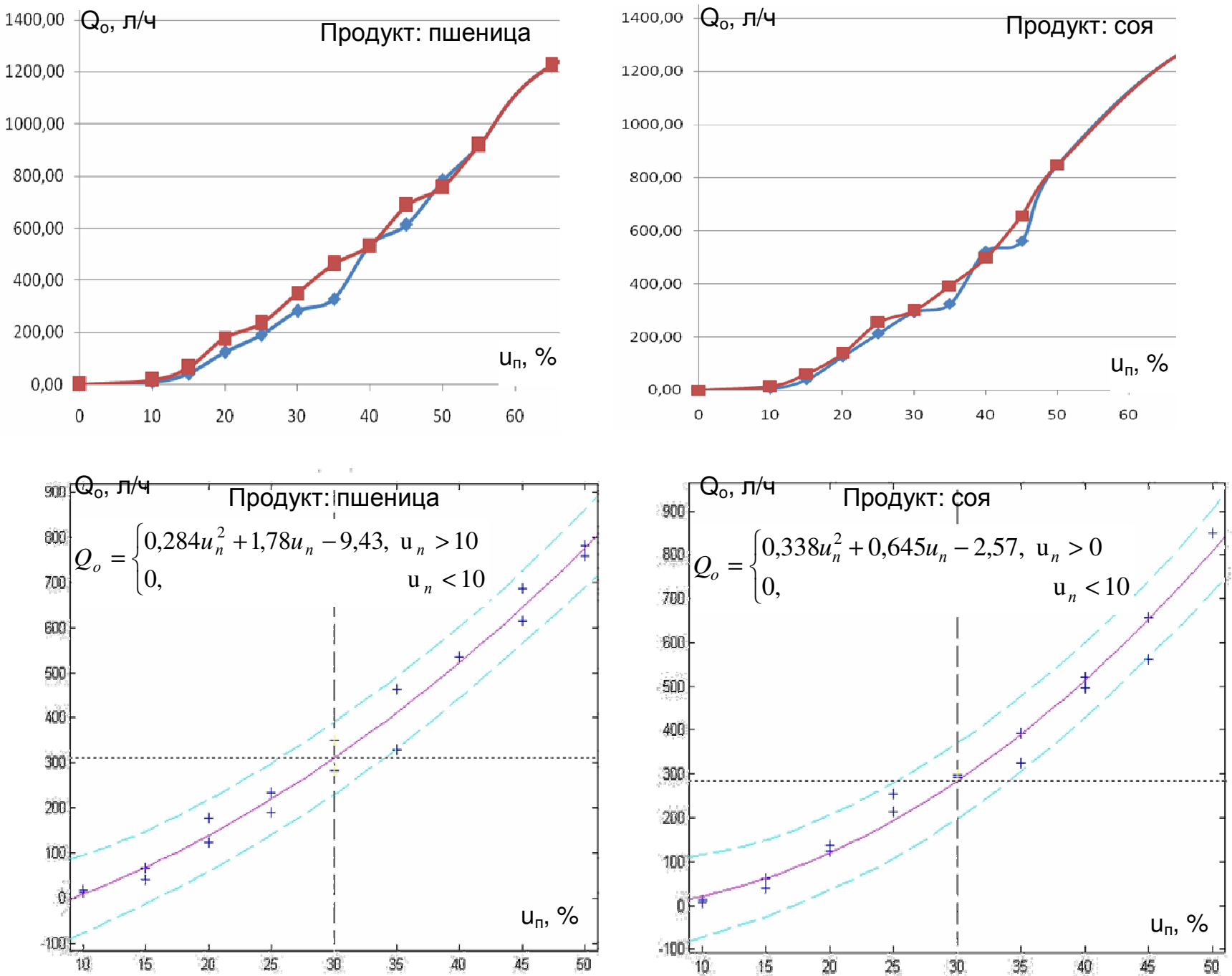

Рис. 1. Статические характеристики вибропитателя экструдера типа Е3-150 для различных продуктов и его модели 
существенное различие в динамике прямых и перекрестных каналов управления, связанных с изменением тока Привода электро-двигателя (ПЭД) и температур экструдата во всех зонах. Это, в определенной мере, упростило задачи исследований, т.к. позволило рассматривать динамику этих каналов относительно независимой. На рис.

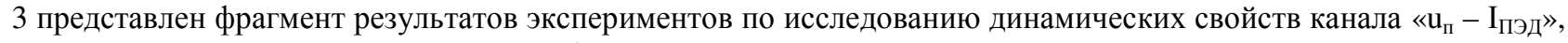
а на рис. 4 - пример процедуры идентификации его типовых моделей динамики первого и второго порядков с запаздыванием [8]. На рис. 5 представлен фрагмент результатов экспериментов по исследованию динамических свойств прямых и перекрестных каналов управления температурными режимами прессования и экструдирования, а также пример процедуры и результатов параметрической идентификации типовых моделей первого порядка с запаздыванием по результатам этих экспериментов [8].

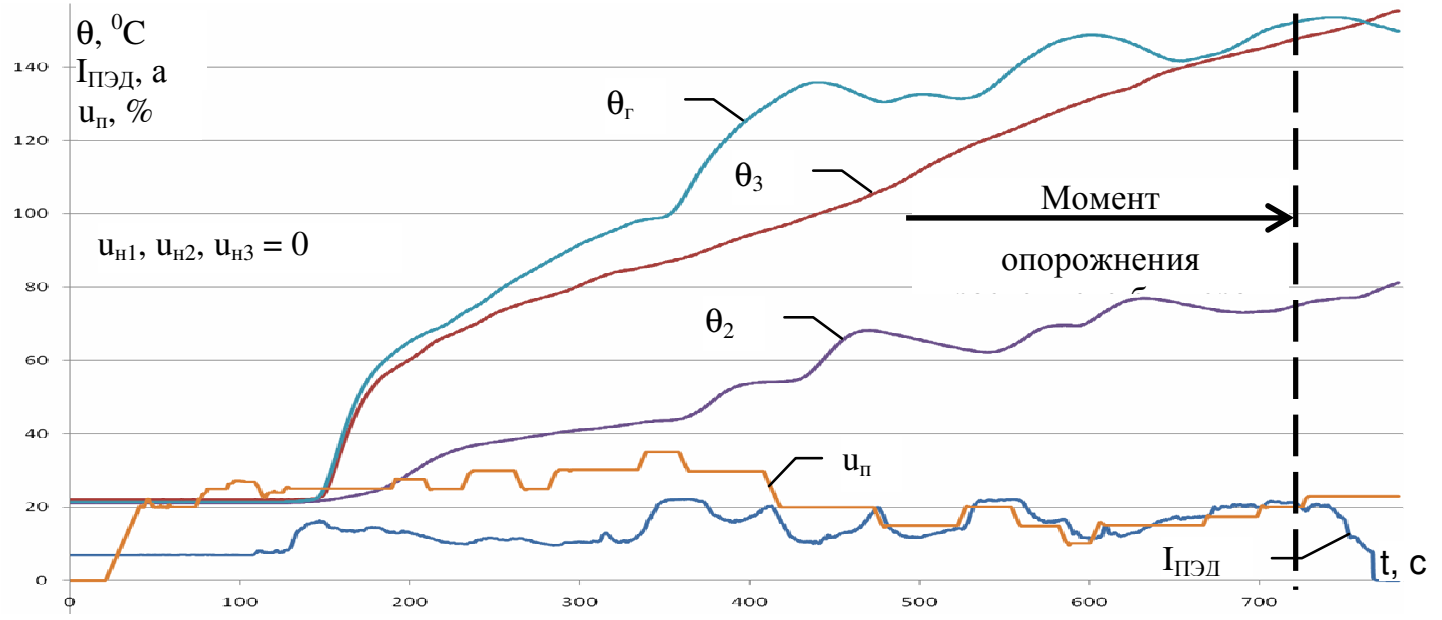

Рис. 2. Фрагменты результатов совместного исследования динамики изменения всех регулируемых переменых при изменениях подачи продукта на экструдирование

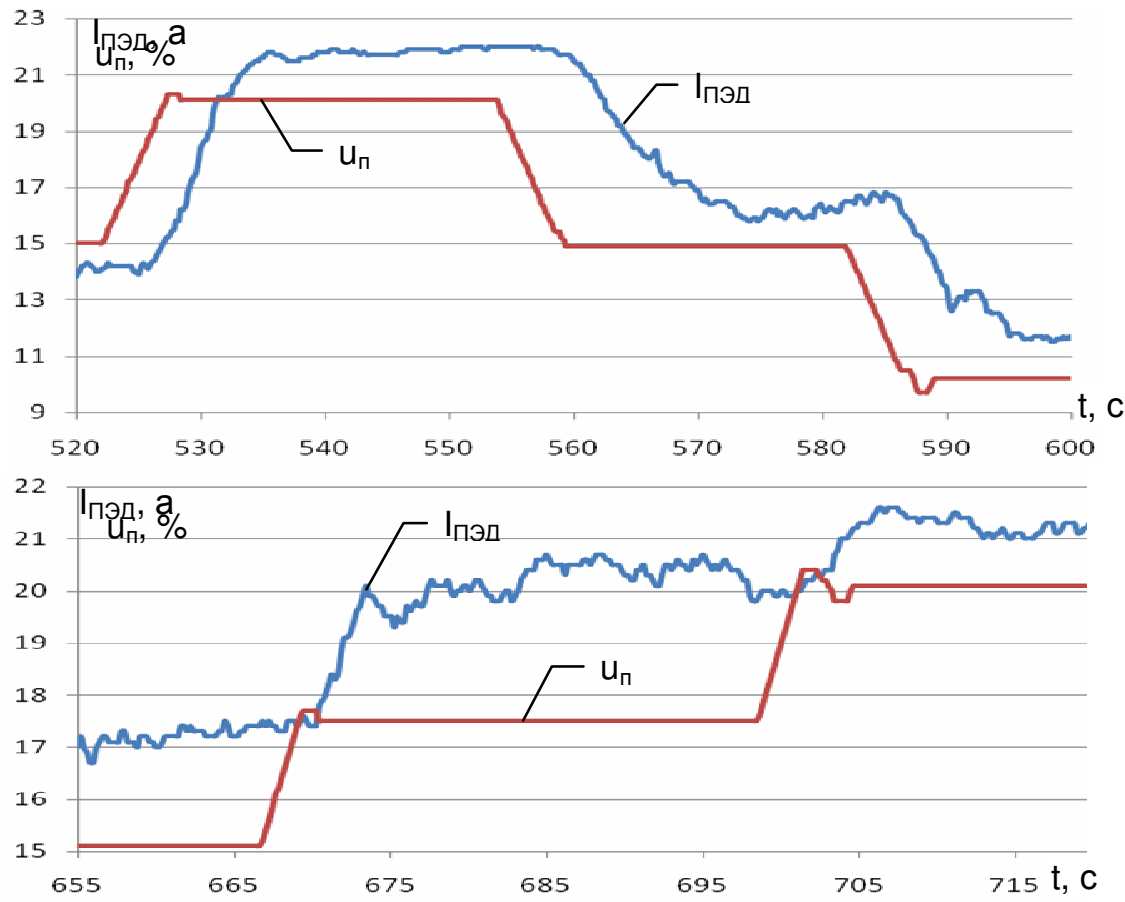

Рис. 3. Фрагменты результатов экспериментальных исследований

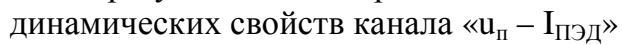


Файл: SPADTOK. IDD

METOR $2-X$ OБUИX TOYEK

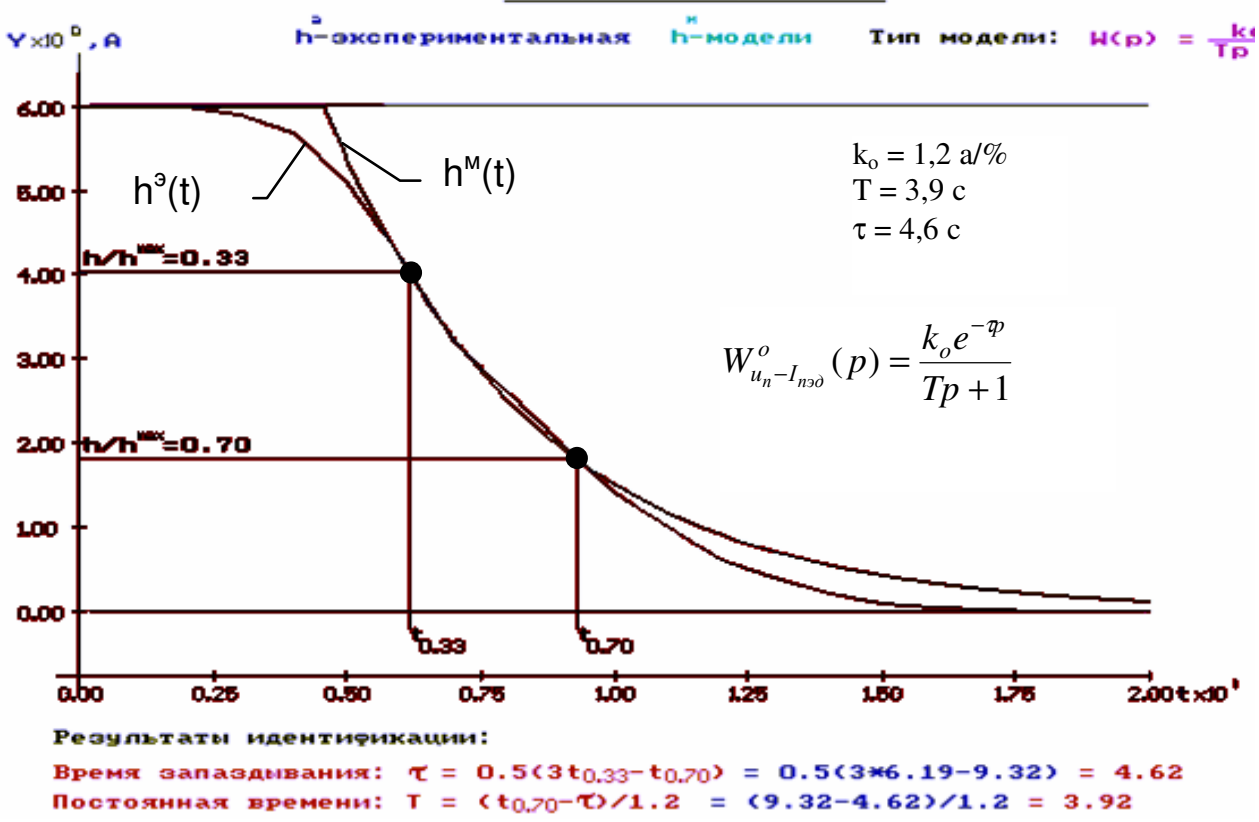

Файл: SPADTOK.IDD МЕTOД $2-X$ ОБЩИХ ТОЧЕК ДЛЯ МОДЕЛИ 2 -ГО ПОРЯДКА

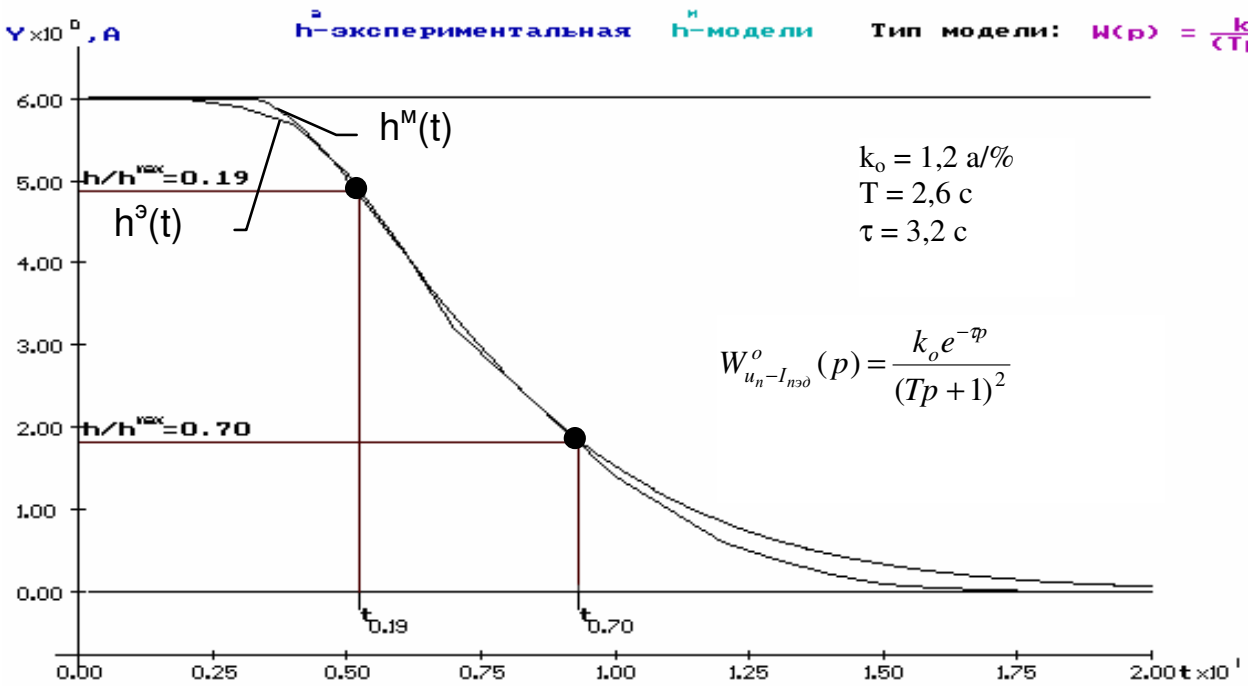

Результаты идентияикаиии:

Время запаздывания: $\tau=0.5\left(3 t_{0.19-t}\right)=0.5(3 * 5.24-9.32)=3.20$

Постоянная времени: $T=\left(t_{0.70}-\tau / 2.4=(9.32-3.20) / 2.4=2.55\right.$

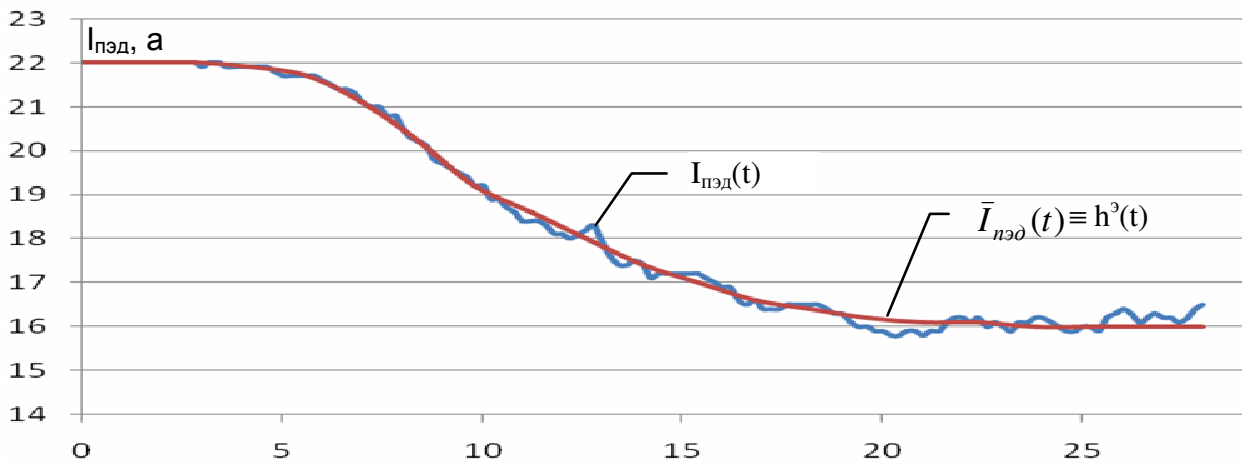

Рис. 4. Пример фильтрации Iпэд от случайной составляющей, процедуры и результатов параметрической идентификации типовых моделей первого и

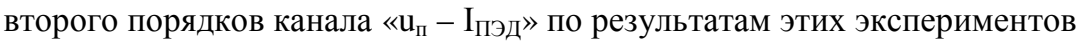
(методики «двух общих точек» Мининой) 


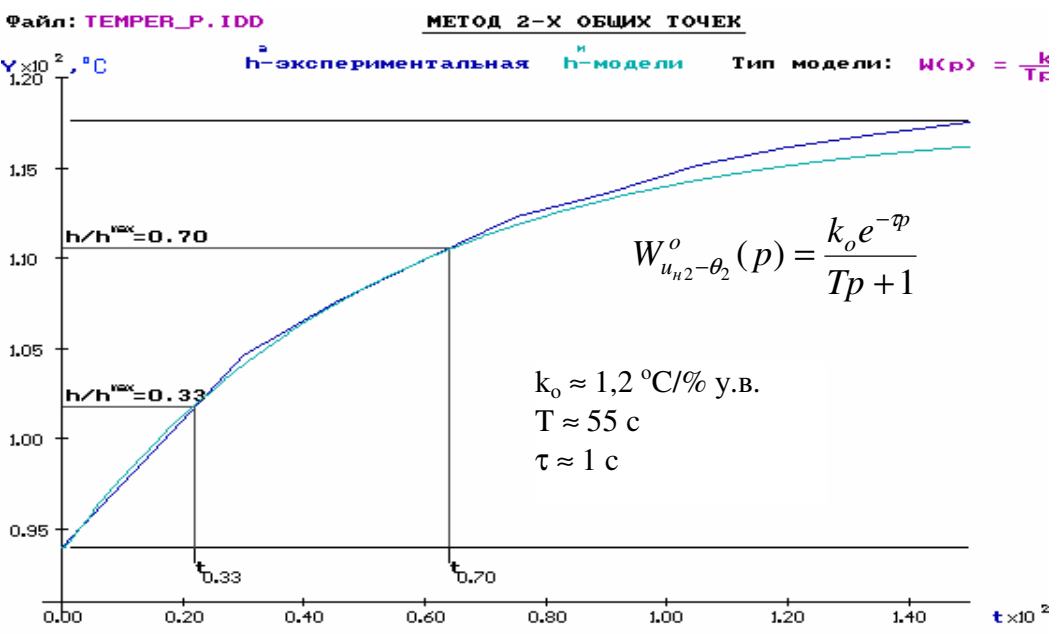

Результаты ияентичикаиии:

Время запаздывания: $\tau=0.5\left(3 t_{0.33^{-}} t_{0.70}\right)=0.5(3 * 21.96-64.02)=0.93$

Постоянная времени: $T=\left(t_{0.70}-\tau\right) / 1.2=(64.02-0.93) / 1.2=52.58$

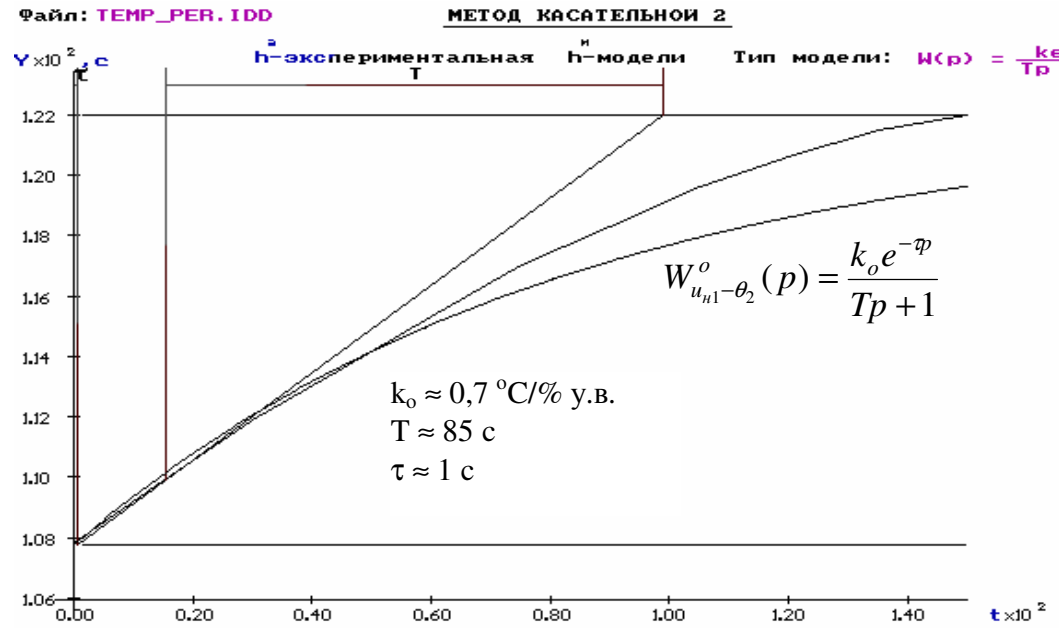

Результаты идентичикаиии:

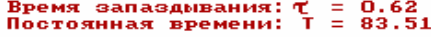

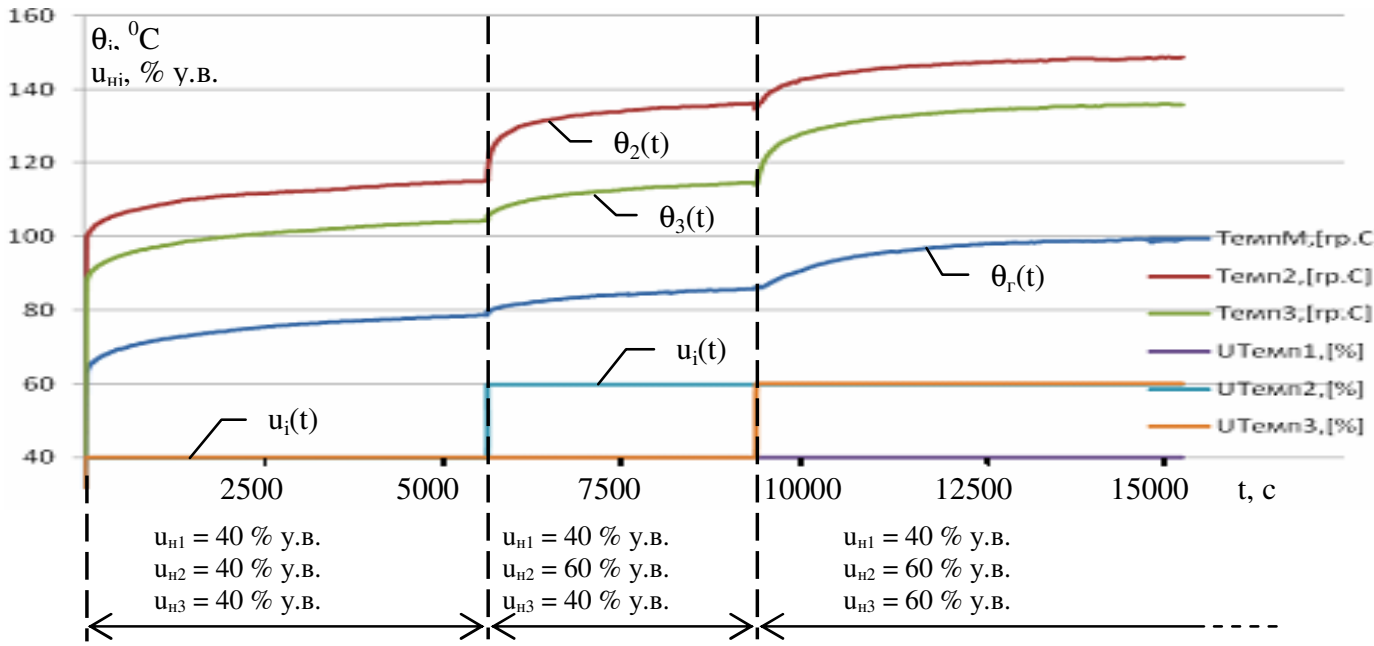

Рис. 5. Фрагмент результатов получения экспериментальных переходных характеристик по прямым и перекрестным каналам управления температурными режимами прессования и экструдирования, пример процедуры и результатов параметрической идентификации типовых моделей первого порядка по результатам этих экспериментов (методика «двух общих точек» Мининой и модифицированная методика «касательной» Кумпфмюллера) 
Принципиально важно, что процесс нагрева зон прессования и головки экструдера ТЭНами является процессом с распределенными параметрами. Для упрощения получения его ММ целесообразно перейти от модели с распределенными параметрами к ячеистой модели [9 - 11]. Ячейки, параметры которых будем считать сосредоточенными, взяты в соответствии с конструктивными особенностями экструдера. Их четыре: три зоны, где расположены ТЭНы и головка экструдера. Все они имеют датчики температуры. Подчеркнем, что эти датчики измеряют температуру не продукта, а соответствующих механических конструкций. Выходными переменными моделей нагрева зон являются их температуры $\theta_{\mathrm{i}}, \mathrm{i}=\overline{1 ; 4}, \theta_{4} \equiv \theta_{\mathrm{r}}$, а входными переменными являются управляющие воздействия на ТЭНы $-u_{H_{i}}, \mathrm{i}=\overline{1,3}$, температуры «предыдущих» и «последующих зон» $\theta_{i-1}, \theta_{i+1}$, температура окружающей среды $\theta_{\text {оc }}$, и переменные, изменяющие $\theta_{\mathrm{i}}$ за счет изменения температуры продукта $\mathrm{T}_{\text {проді }}$, обозначенные на схеме имитационного моделирования (см. следующий пункт раздела) как $+\mathrm{dT}_{\mathrm{i}}$ и $-\mathrm{dT}$. В единую модель отдельные модели ячеек (зон) объединяют перекрестные связи, описывающие процессы теплообмена между зонами. Отметим, что переменные $\mathrm{T}_{\text {проді }}$ и $\pm \mathrm{dT}_{\mathrm{i}}$ в реальных условиях измерены быть не могут, поэтому эти переменные присутствуют в явном виде (как и их обозначения) только в имитационной модели процесса. Модель каждой ячейки (зоны) учитывает изменение ее температуры не только за счет подвода тепловой энергии от ТЭНа, но и за счет теплообмена с экструдируемым продуктом, который может, как повышать, так и понижать температуру зоны, а также теплообмен с окружающей средой [12-14].

Процесс движения экструдируемого материала вдоль оси экструдера также является процессом с распределенными параметрами (по координате перемещения) [9 - 11]. Он также описывается нами ячеистой моделью аналогичной структуры. Входными переменными этих моделей являются: температура окружающей среды - $\theta_{\text {o.c. }}\left(\mathrm{Temp} \_\mathrm{okr} \_s r\right)$; температура нагрева зон экструдера $-\theta_{\mathrm{i}}$ (Тетрі); влажность продукта (сырья) на входе в экструдер - W; расход продукта (производительность питателя) - $\mathrm{Q}_{\mathrm{o}}$; время перемещения продукта до первой зоны, время пребывания продукта в каждой из зон - тau_zonei. В единую модель отдельные модели ячеек, т.е. модели движения продукта в і-тых зонах объединяют: а) последовательные связи по температурам продукта в зонах $\mathrm{T}_{\text {проді }}$ б) параллельные связи по «затратам» относительного момента вращения на валу ПЭД - $\mathrm{dM}_{\mathrm{i}}$; в) обратные связи по $\pm \mathrm{dT}$, замыкающиеся через соответствующие модели нагрева і-тых зон. Выходными переменными моделей движения продукта по зонам являются: температуры продукта на выходе каждой зоны Т проді относительный момент сопротивления $\mathrm{dM}$, приведенный к валу ПЭД и связанный с совершением работы по деформации и перемещению

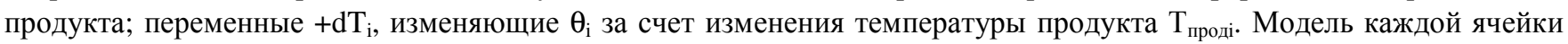
учитывает время пребывания продукта в каждой зоне, затраты механической энергии на нагрев продукта, источником которой является ПЭД экструдера, и которая переходит в тепло за счет внутреннего трения в продукте при его деформации и внешнего трения продукта о цилиндрические стенки и винтовую поверхность шнека, в т.ч. при изменении его расхода и влажности [12 - 14]. Подчеркнем следующие особенности этих моделей: а) выходные переменные моделей на реальном экструдере физически не измеряются (это уже отмечалось ранее), т.к. это либо представляет собой значительные технические трудности, либо принципиально невозможно; б) в силу п. «а» эти переменные не могут непосредственно быть использованы в процедурах идентификации моделей и/или проверки их адекватности.

Выводы. Технология экспериментально-эвристического подхода, принятая для разработки ММ процесса ЭБП как ОУ, показала свою эффективность. Она проявилась в том, что на основе ограниченного количества экспериментов была получена физически обоснованная и адекватная модель. Эта эффективность, на наш взгляд, обусловлена тем, что при экспериментально-эвристическом подходе объединяются знания объективные, суть которых - характеристики процесса, получаемые в ходе натурных экспериментов, и знания субъективные, суть которых - понимание разработчиком модели физической сущности протекающих процессов. Реализация модели в имитационной форме снимает все ограничения на разработку сложных, в т.ч. существенно нелинейных, алгоритмов управления. При этом специальная организация машинных экспериментов с имитационными моделями САУ, в том числе оптимизационных и вероятностных экспериментов, позволит проводить настройку и тестирование алгоритмов таким образом, чтобы разработанная САУ соответствовала бы двум важным, но противоречивым принципам: оптимальности и робастности.

\section{Литература}

1. Штейнберг Ш.Е. Идентификация в системах управления. - М.: Энергоатомиздат, 1987. - 80 с.

2. Льюинг Л. Идентификация систем. Теория для пользователя: Пер. с англ. - М.: Наука, 1991. - 432 с.

3. Егоров. В.Б. Повышение эффективности систем автоматического управления процессом экструдирования биополимеров. Кандидатская диссертация. 2013. - 249 с;

4. Скурихин В.И. и др. Математическое моделирование / В.И. Скурихин, В.Б. Шифрин, В.В. Дубровский. - К.: Техніка, 1983. - 270 с., ил.

5. Структурное моделирование сложных динамических систем / Г.Л. Баранов, А.В. Макаров. - Киев: Наукова думка, 1986. - 272 с. 


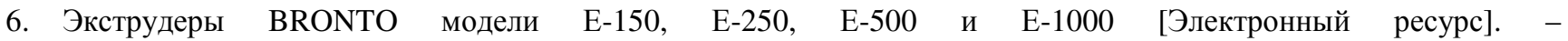
http://www.tradingfirm.org/ext.html.

7. Экструдеры BRONTO ${ }^{\mathrm{TM}}$ зерновые, соевые [Электронный ресурс]. - http://www.ekko.com.ua/?newsid=26.

8. Минина О.М. Определение динамических характеристик и параметров регулируемых процессов. - М.: Изд-во АН СССР, 1963. - 46 с.

9. Демиденко Н.Д. Моделирование и оптимизация систем с распределенными параметрами // В.И. Потапов, Ю.И. Шокин. - Новосибирск: Наука, 2006. - 551 с.

10. Кафаров В.В., Глебов М.Б. Математическое моделирование основных процессов химических производств: Учеб. пособие для вузов. - М.: Высш. шк., 1991. - 400 с.: ил.

11. Остапчук Н.В. Основы математического моделирования процессов пищевых производств: Учеб. пособие. - 2е изд., перераб. и доп. - К.: Выщ. шк., 1991. - 367c.

12. Нащокин В.В. Техническая термодинамика и теплопередача. - М.: «Высшая школа», 1975. - 145 с.

13. Баскаков А.П., Берг Б.В., Витт О.К. Теплотехника. - М.: Энергоатомиздат, 1991. - 224 с.

14. Гинзбург А.С., Громов М.А. Теплофизические свойства зерна, муки и крупы. - М.: Колос, $1984 .-304$ с.

\section{ОБ УПРАВЛЕНИИ ЭФФЕКТИВНОСТЬЮ ТЕХНОЛОГИЧЕСКОГО ОБОРУДОВАНИЯ, ИСЧЕРПАВШЕГО РЕСУРС}

\author{
Воинова С. А., канд. техн. наук, доцент, \\ Одесская национальная академия пищевых технологий
}

Аннотация: Рассмотрена задача повышения эффективности использования технологического оборудования, отработавшего расчетный ресурс.

Анотація: Розглянуто задачу підвищення ефективності використання технологічного устаткування, що відпрацювало розрахунковий ресурс.

Annotation: The problem of increase of efficiency of use of the process equipment which has fulfilled a rated resource is considered.

Ключевые слова: управление, эффективность, технологическое оборудование, ресурс, обновление.

Затянувшийся период развития мирового производства по стагнационному сценарию негативно влияет на состояние основных фондов всех без исключения отраслей государственного хозяйства. Наиболее жесткому влиянию подверглись тяжелое, энергетическое и транспортное машиностроение. Действие этих объективных обстоятельств в полной мере ощущает производственная сфера Украины. Одной из черт нынешнего состояния значительной части отечественных предприятий является пребывание их оборудования в предельном состоянии, которое наступило после исчерпания этим оборудованием расчетного (паркового) ресурса работоспособности, вследствие предельно допустимого износа. Согласно мировому подходу, подобное оборудование нецелесообразно ни ремонтировать, ни эксплуатировать. Его надлежит заменить новым оборудованием. Подобная возможность в Украине, еще не сформировалась. Технологические показатели оборудования, отработавшего ресурс, низки.

Коснемся модели процесса изменения во времени состояния действующего ТО. Как известно, степень функционального совершенства технологического процесса и осуществляющего его технического объекта (ТО) характеризуют уровнем технологической эффективности (ТЭ), уровнем ее составляющих - экологической, экономической и общетехнической $[1,2]$. Новый ТО в момент ввода его в действие обладает наивысшей ТЭ исходной $\left(\mathrm{TЭ}_{\text {исх }}\right)$. С течением времени, вследствие износа ТО, его ТЭ непрерывно снижается до уровня потенциальной ТЭ - (ТЭп). Фактическая (наблюдаемая) ТЭ - (ТЭ $)$ уступает ТЭ , если алгоритм системы автоматического управления (САУ) объектом соответствует исходному состоянию ТО [1, 2].

Значительную часть используемого в промышленности технологического оборудования составляют изношенные TO. Они обладают низким уровнем ТЭ. Это положение временно приходится терпеть, так как ресурсные возможности еще не созрели для коренного, радикально улучшения обстановки путем замены изношенного оборудования новым, современным, инновационно насыщенным. 